\title{
Performance Effects of Laser Deposited Ti-Al-Sn Coating on ASTM A29 Steel
}

\author{
O.S. Fatoba ${ }^{1, \mathrm{a}^{*}}$, S.A. Akinlabi ${ }^{2, \mathrm{~b}}$ and E.T. Akinlabi ${ }^{1, \mathrm{c}}$ \\ ${ }^{1}$ Department of Mechanical Engineering Science, Faculty of Engineering and the Built Environment, \\ University of Johannesburg, South Africa \\ ${ }^{2}$ Department of Mechanical and Industrial Engineering Technology, Faculty of Engineering and the Built \\ Environment, University of Johannesburg, South Africa \\ adrfatobasameni@gmail.com, ${ }^{b}$ stephenakinlabi@gmail.com, ${ }^{c}$ etakinlabi@uj.ac.za
}

Keywords: ASTM A29 Steel, Hardness, Wear, Ti-Al-Sn Coating, Intermetallics

\begin{abstract}
The conventional surface modification and coating cannot always fulfil the performance of material surface under extreme corrosion and wear environments. Corrosion and wear phenomenon lead to the gradual deterioration of components in industrial plants that can result in loss of plant efficiency, and even total shutdown with aggravated damage in industries. Hence, surface modification by incorporating chemical barrier coatings can be beneficial to this extent we report on investigation aimed at enhancing the surface properties of ASTM A29 steel by incorporating Ti-Al-Sn coatings deposited by laser deposition technique. For this purpose, a $3-\mathrm{kW}$ continuous wave ytterbium laser system attached to a KUKA robot which controls the movement during the alloying process was utilized to deposit coatings with stoichiometry Ti30Al-20Sn and Ti-20Al-20Sn. The alloyed surfaces were investigated in terms of its hardness and wear behaviour as function of the laser processing conditions. Hardness measurements were done using a vickers micro-hardness tester model FM700. Wear tests were performed on prepared ASTM A29 steel substrate deposited sample using the reciprocating tribometer (CERT UMT-2) under dry reciprocating conditions with continual recording of the dynamic coefficient of friction (COF) values. The microstructures of the coated and uncoated samples were characterized by optical and scanning electron microscopy. In addition, X-ray diffraction was used to identify the phase's contents. The optimum performances were obtained for an alloy composition of Ti-20Al-20Sn, at laser power of $750 \mathrm{~W}$ and coating speed of $0.8 \mathrm{~m} / \mathrm{min}$. Its performance enhancement compared to the unprotected substrate comprised a significant increase in hardness from 115 to $509 \mathrm{HV}$ and reduced wear volume loss from 0.717 to 0.053 $\mathrm{mm}^{3}$. The enhanced performance is attributed to the formation of the intermetallic phases $\mathrm{Ti}_{6} \mathrm{Sn}_{5}, \mathrm{AlSn}_{2} \mathrm{Ti}_{5}, \mathrm{Ti}_{3} \mathrm{Al}$, and TiAl.
\end{abstract}

\section{Introduction}

Al-Sn based alloys are widely used as sliding bearing materials in automobile and shipbuilding industry due to their good compact ability, wear resistance, thermal conductivity, and sliding properties [1]. The alloys also excel in high temperature stability. In these alloy systems, tin is a necessary soft phase in the aluminium matrix. Due to its low modulus, low strength and the excellent anti-welding characteristics with iron, tin phase in Al-Sn bearing materials can provide suitable frictional properties and shear surface during sliding [1]. The development of uniform microstructures with improved performance has been necessitated by the growing importance of Al-Sn based alloys as materials for engineering applications [2]. However, the processing of these alloys by conventional liquid metallurgy routes results in coarse grain microstructure with large degree of segregation of alloying elements [3]. Nevertheless, literature on hardness and 
wear resistance performance of Ti-Al-Sn alloy coatings on ASTM A29 steel by laser surface alloying (LSA) technique are very scarce. LSA can rapidly provide a thick and crack-free layer in all instances with metallurgical bonds at the interface between the alloyed layer and the substrate. Powders surfaced on new or worn working surfaces of components by LSA provides specific properties such as high abrasive wear resistance, erosion resistance, corrosion resistance, heat resistance and combinations of these properties. Consequently, improvements in machinery performance and safety in aerospace, automotive, can be realized by the method [4]. The present study investigates the effect of laser processing parameters on the hardness and wear resistance performance of Ti-Al-Sn coatings on ASTM A29 steel.

\section{Experimental details}

Materials Specifications and Sample Preparation Method. The substrate material used in the present investigation was ASTM A29 steel. The substrate was cut, and machined into dimensions $100 \times 100 \times 5 \mathrm{~mm}^{3}$. Prior to laser treatment, the substrates (ASTM A29 steel) were sandblasted, washed, rinsed in water, cleaned with acetone and dried in hot air before exposure to laser beam to minimize reflection of radiation during laser processing and enhance the absorption of the laser beam radiation. Ti (99.9\% purity), Al (99.9 \% purity) and Sn (99.9 \%) reinforcement metallic powders were mixed in 60:20:20(A1), 60:20:20(A2), 50:30:20(B1), 50:30:20(B2) ratio, respectively, in a shaker mixer (Turbular T2F; Glenn Mills, Inc.) for 12 hours at a speed of $49 \mathrm{rpm}$ to obtain homogeneous mixture. The particle shape of the powder used was spherical with 50-105 $\mu$ m particle sizes.

Wear tests were performed on the deposited sample at room temperature using the reciprocating tribometer (CERT UMT-2; Bruker Nano Inc., Campell, CA) under dry reciprocating conditions with continual recording of the dynamic coefficient of friction values. The normal load applied on the samples was $25 \mathrm{~N}$ at a frequency of $5 \mathrm{~Hz}$ and $2 \mathrm{~mm}$ stroke length using tungsten carbide (WC) counter material. Laser surface alloying was performed using a 3$\mathrm{kW}$ continuous wave (CW) Ytterbium Laser System (YLS) controlled by a KUKA robot which controls the movement of the nozzle head and emitting a Gaussian beam at $1064 \mathrm{~nm}$. The nozzle was fixed at $3 \mathrm{~mm}$ from the steel substrate. The admixed powders were fed coaxially by employing a commercial powder feeder instrument equipped with a flow balance to control the powder feed rate. The metallic powder was fed through the off-axes nozzle fitted onto the Ytterbium fibre laser and it was injected simultaneously into a melt pool formed during scanning of the ASTM A29 steel by the laser beam. Argon gas flowing at a rate of $2.5 \mathrm{~L} / \mathrm{min}$ was used as a shielding gas to prevent oxidation of the sample during laser surface alloying. Overlapping tracks were obtained by overlapping of melt tracks at $70 \%$. To determine the best processing parameters, optimization tests were performed with the laser power of 750 to $900 \mathrm{~W}$ and scanning speed varied from 0.6 to $0.8 \mathrm{~m} / \mathrm{min}$. The final selection criteria during optimization tests was based on surface having homogeneous layer free of porosity and cracks determined from SEM analysis. The optimum laser parameters used was $900 \mathrm{~W}$ power, a beam diameter of 3 $\mathrm{mm}$, gas flow rate of $2.5 \mathrm{~L} / \mathrm{min}$, powder flow rate of $2.0 \mathrm{~g} / \mathrm{min}$ and scanning speeds of $0.6 \mathrm{~m} / \mathrm{min}$ and $0.8 \mathrm{~m} / \mathrm{min}$ respectively.

According to $\mathrm{Qu}$ and Truhan [5], the wear depth $\mathrm{Zw}$ and wear volume of the flat specimen can be calculated with the following equations:

$$
V_{W}=L_{S}\left[R_{S}{ }^{2} \sin ^{-1}\left(\frac{W}{2 R_{S}}\right)-\frac{W}{2}\left(R_{S}-Z_{W}\right)\right]+\frac{\pi}{3} Z_{W}{ }^{2}\left(3 R_{S}-Z_{W}\right)
$$




$$
Z_{W}=R_{S}-\sqrt{R_{S}{ }^{2}-\frac{W^{2}}{4}}
$$

Where $Z_{\mathrm{W}}=$ Wear depth; $\mathrm{R}_{\mathrm{S}}=$ Radius of spherical surface at both ends; $\mathrm{W}=$ Width of the wear scar

$\mathrm{V}_{\mathrm{W}}=$ Wear Volume; $\mathrm{L}_{\mathrm{S}}=$ Stroke length

\section{Results and discussion}

Morphological and Phase Analyses of Ti-Al-Sn Ternary Coatings. Intermetallic phases Ti, $\mathrm{Al}_{5} \mathrm{Ti}_{2}, \mathrm{Al}_{3} \mathrm{Ti}$, and $\mathrm{Sn}_{5} \mathrm{Ti}_{6}$ are common to alloyed samples at laser speed of 0.6 and $0.8 \mathrm{~m} / \mathrm{min}$. More peaks with smaller interspacing distance of order 2.75 to $1.34 \AA$ were visible in the XRD spectrum showed in Fig. 1. Furthermore, there is good evidence of Al, Sn and Ti metal in the XRD spectrum. The presence of $\mathrm{Al}, \mathrm{Sn}$ and $\mathrm{Ti}$ after laser alloying process formed three major hard phases of aluminium-titanium $\left(\mathrm{AlTi}_{2}, \mathrm{Al}_{5} \mathrm{Ti}_{2}, \mathrm{Al}_{3} \mathrm{Ti}, \mathrm{AlTi}_{3}, \mathrm{Al}_{2} \mathrm{Ti}, \mathrm{Al}_{2} \mathrm{Ti}\right)$, tin-titanium $\left(\mathrm{Sn}_{5} \mathrm{Ti}_{6}\right)$, and aluminium-tin-titanium $\left(\mathrm{AlSn}_{2} \mathrm{Ti}_{5}\right)$. The phases formed showed good interfacial bonding and evidence of reactions occurring between $\mathrm{Al}$ and $\mathrm{Ti}, \mathrm{Al}, \mathrm{Sn}$ and Ti, Sn and Ti. The reaction between elemental powders of $\mathrm{Ti}$ and $\mathrm{Al}$ led to the formation of $\mathrm{TiAl}_{3}, \mathrm{Ti}_{3} \mathrm{Al}$, and $\mathrm{TiAl}$ according to the binary phase diagram of Ti-Al. The formation of titanium-aluminides intermetallics took place through an exothermic reaction between solid titanium and liquid aluminium [6]. On the other hand, $\mathrm{TiAl}_{2}$ and $\mathrm{Ti}_{2} \mathrm{Al}_{5}$ would require $\mathrm{TiAl}$ as an intermediate product for their formation [6].

Grain refinement effect of titanium which plays a vital function in influencing the critical properties of aluminium products have been studied by previous researchers. It enhances plasticity and tensile intensities and reduces the tendency of porosity and hot tearing [7]. This is due to the peritectic reaction occurrence at the end of aluminium rich in aluminium-titanium phase diagram [8]. It was clearly observed from the XRD spectrum of laser alloyed samples in Fig. 1 the presence of aluminium-titanium phases in five different forms such as $\mathrm{AlTi}_{2}, \mathrm{Al}_{5} \mathrm{Ti}_{2}$, $\mathrm{Al}_{3} \mathrm{Ti}, \mathrm{AlTi}_{3}$, and $\mathrm{Al}_{2} \mathrm{Ti}$. The aluminium-titanium phases increase as the laser speed increases from 0.6 to $0.8 \mathrm{~m} / \mathrm{min}$. It indicates that as the speed decreases, there is good possibility for Al to react with $\mathrm{Ti}$. In addendum, titanium-aluminides such as $\mathrm{Ti}_{3} \mathrm{Al}$ and $\mathrm{TiAl}$ exhibit significant potential to be a good alternative to existing conventional iron-aluminides, titanium alloys, and nickel super-alloys [9]. Fig. 1 shows intermetallic compounds with evidence of aluminiumtitanium ( $\left.\mathrm{AlTi}_{2}, \mathrm{Al}_{5} \mathrm{Ti}_{2}, \mathrm{Al}_{3} \mathrm{Ti}, \mathrm{AlTi}_{3}, \mathrm{Al}_{2} \mathrm{Ti}\right)$, tin-titanium $\left(\mathrm{Sn}_{5} \mathrm{Ti}_{6}\right)$, and aluminium-tin-titanium $\left(\mathrm{AlSn}_{2} \mathrm{Ti}_{5}\right)$. It can also be observed that as the laser speed increases from 0.6 to $0.8 \mathrm{~m} / \mathrm{min}$ there are smaller grain sizes of the various phases formed. This could be attributed to the fact that increases in laser speed led to faster cooling of the melt pool which resulted into the fine grain sizes as shown in Fig. 2.

Moreover, according to Akinlabi and Akinlabi [10], increase in number of scan changes to type of heat treatment and produces strain hardening in material causing the grain sizes to be reduced as laser scans increases. In addendum, increase of the scanning speed results in finer microstructure due to the larger cooling rate during solidification as reported by Gong et al. [11]. Fig. 2 shows a microstructure without pores. It is well known that porosity results from gas bubbles trapped in the melt pool when the front wall solidifies [12] and this is influenced by laser scanning speed. 


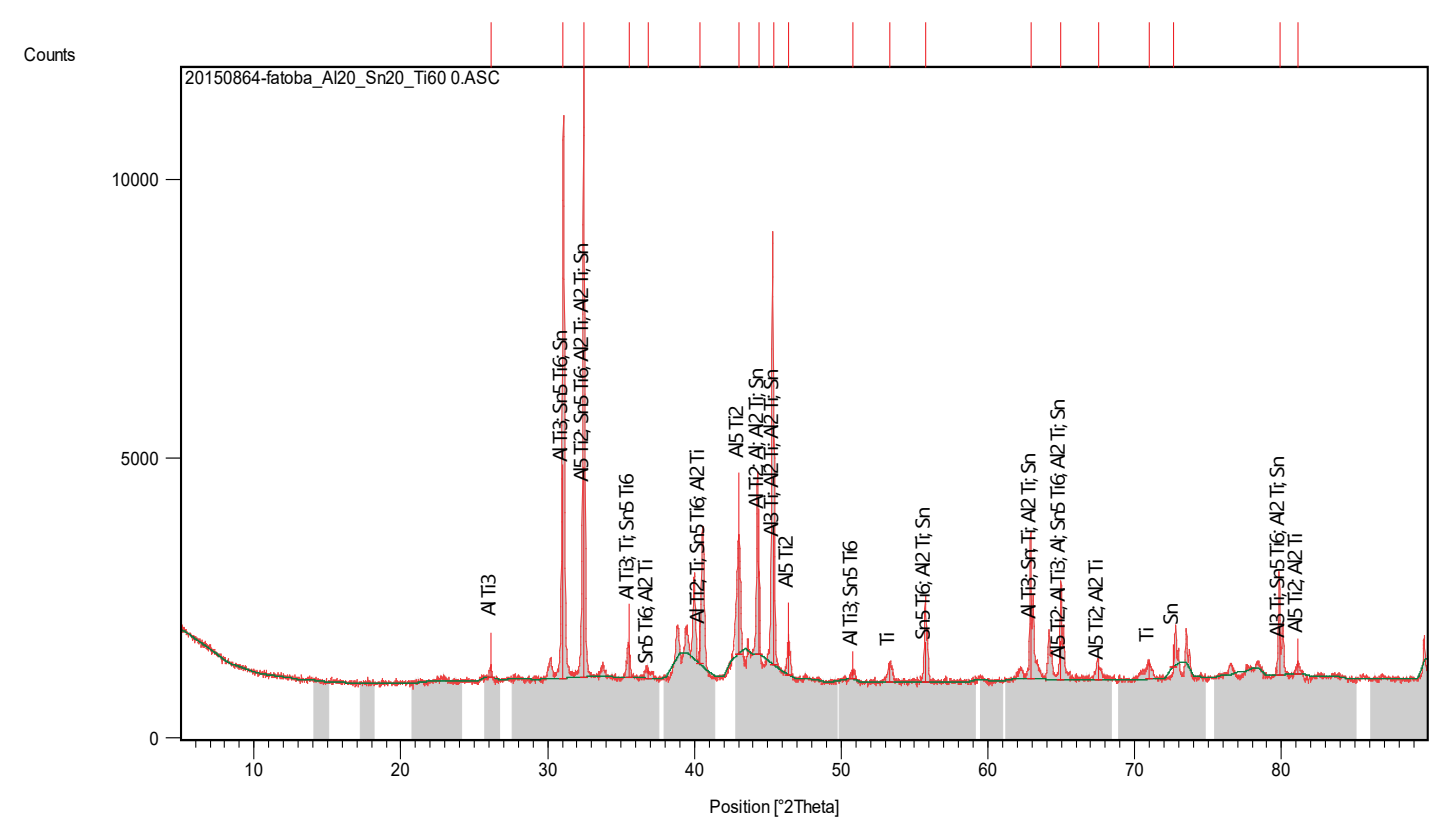

Fig. 1: XRD Spectrum of Ti-20Al-20Sn-0.8 Ternary Coating.

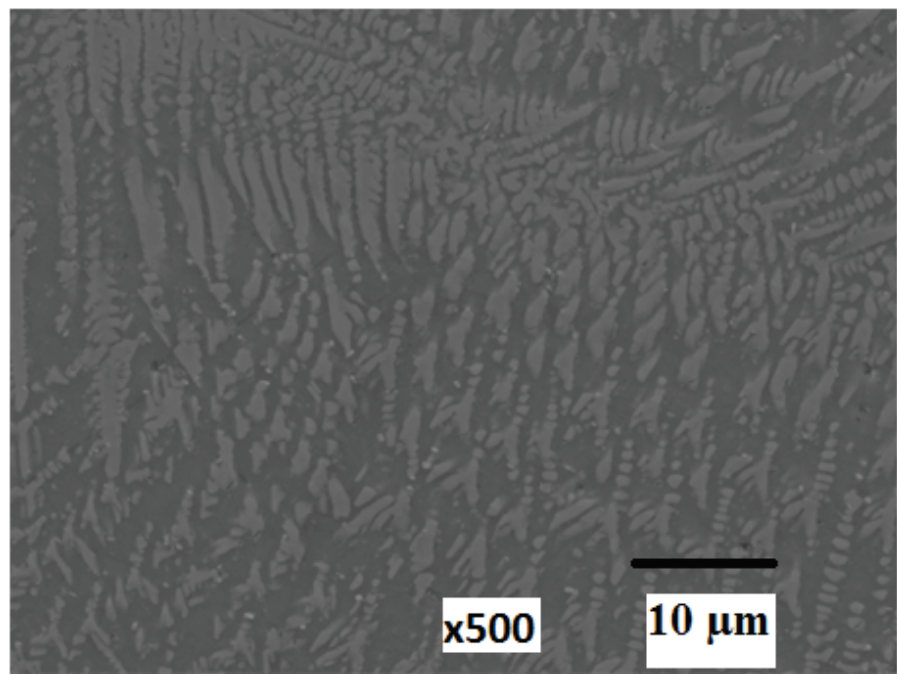

Fig. 2: SEM Images of Ti-20Al-20Sn Ternary Coating at $0.8 \mathrm{~m} / \mathrm{min}$ scanning speed.

Microhardness Property of Ti-Al-Sn Ternary Coatings. The results showed that the laser alloying process enhances the hardness value of the substrate as shown in Fig. 3. Hardness values range between 115 to $509 \mathrm{HV}$. The hardness values of 115, 288, 376, 476, and $509 \mathrm{HV}$ were obtained for substrate, Ti-30Al-20Sn-0.6, Ti-30Al-20Sn-0.8, Ti-20Al-20Sn-0.6, and Ti20Al-20Sn-0.8 respectively. A raise of 75.84 and $81.51 \%$ in hardness values above that of the substrate at Ti-20Al-20Sn-0.6 and Ti-20Al-20Sn-0.8 respectively. This increased hardness values are attributed to the hard phases of aluminium-titanium $\left(\mathrm{AlTi}_{2}, \mathrm{Al}_{5} \mathrm{Ti}_{2}, \mathrm{Al}_{3} \mathrm{Ti}_{1} \mathrm{AlTi}_{3}\right.$, $\left.\mathrm{Al}_{2} \mathrm{Ti}, \mathrm{Al}_{2} \mathrm{Ti}\right)$, tin-titanium $\left(\mathrm{Sn}_{5} \mathrm{Ti}_{6}\right)$, and aluminium-tin-titanium $\left(\mathrm{AlSn}_{2} \mathrm{Ti}_{5}\right)$ formed after the laser alloying process as evident by the XRD spectrum and SEM image shown in Figs. 1 and 2. 


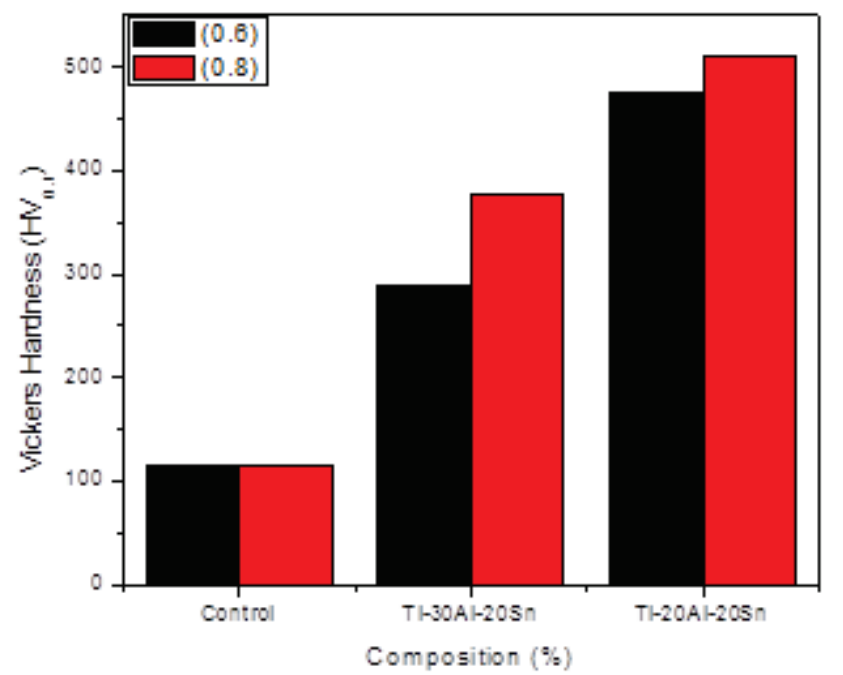

Fig. 3: Comparative Microhardness Chart of the Control and Al-Sn-Ti Ternary Coatings.

Wear Performance of Ti-Al-Sn Coatings. Comparisons of the experimental results show that the friction coefficient attained by ternary coatings was remarkable and range between 0.19 and 0.42 respectively as shown in Fig. 4. In general, the friction coefficient of coated samples indicated remarkable improvement in wear resistance performance compared to the control sample, with $35.38 \%$ and $70.77 \%$ reduction in coefficient of friction of Ti-20Al-20Sn-0.6 and Ti-20Al-20Sn-0.8 respectively. With Eq. 1, the wear volume losses of the control, and coated samples (Ti-20Al-20Sn-0.6, Ti-20Al-20Sn-0.8, Ti-30Al-20Sn-0.6, Ti-30Al-20Sn-0.8) were calculated as $0.72,0.075,0.053,0.083$, and $0.089 \mathrm{~mm}^{3}$ respectively.
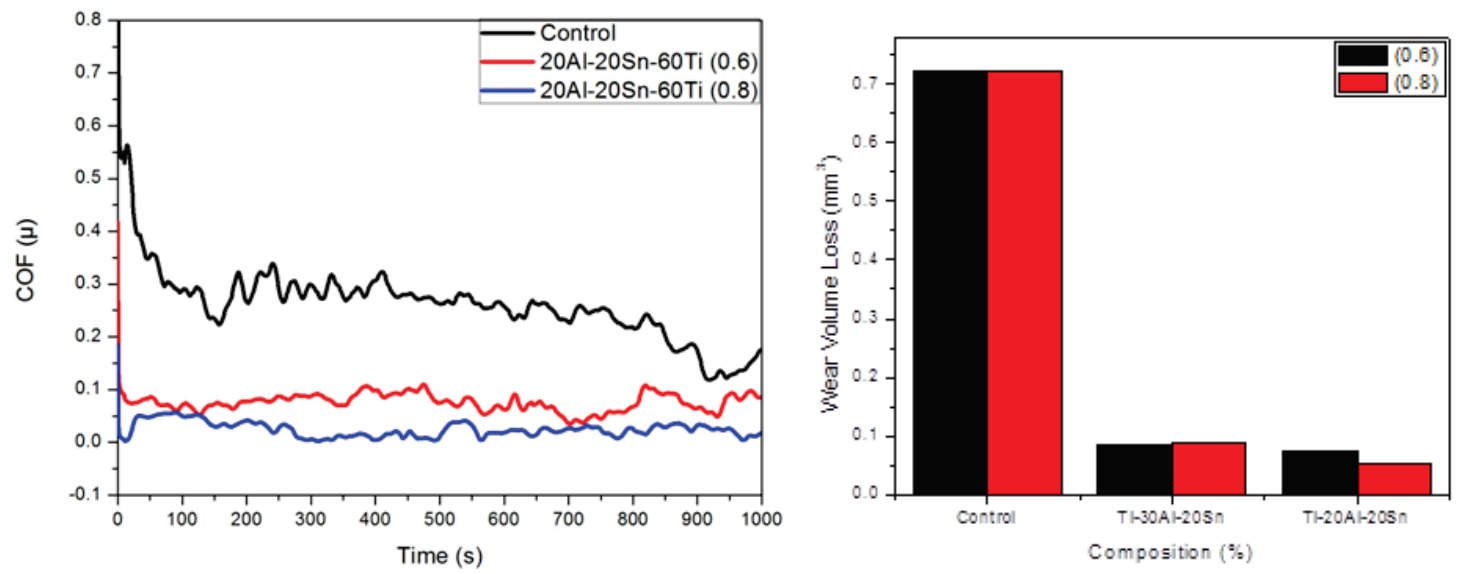

Fig. 4: Variation of the Friction Coefficient with Time and Wear Volume Loss for the Control and Al-Sn-Ti Ternary Coatings.

All the ternary coatings samples showed decrease in plastic deformation with Ti-20Al-20Sn0.8 indicating an outstanding decrease in adhered layer and surface dislocation. The wear losses of ternary coated samples indicated remarkable improvement in wear resistance performance compared to the control sample with $90.38 \%$ and $92.68 \%$ reduction in wear volume losses of Ti-20Al-20Sn-0.6 and Ti-20Al-20Sn-0.8 respectively.

\section{Conclusion}

Well optimized process parameters and carefully chosen reinforcement materials fractions produced coatings with enhanced hardness and wear resistance properties. Crack formation was 
eliminated through optimization of laser processing parameters, leading to enhanced quality of the coatings, surface adhesion between substrate and reinforcement materials, microstructural evolution and thus improved properties.

The composition proportion of mixed powders has a great influence on the phase structure of the laser deposited coatings. In addendum, titanium-aluminides such as $\mathrm{Al}_{3} \mathrm{Ti}$, and $\mathrm{AlTi}_{3}$ formed exhibit significant potential to be a good alternative to existing conventional iron-aluminides. Different titanium aluminide compounds such as $\mathrm{TiAl}_{3}, \mathrm{Ti}_{3} \mathrm{Al}$ and TiAl also influence tribological and mechanical properties.

\section{References}

[1] T. Desaki, Y. Goto and S. Kamiya, Development of the Aluminium Alloy Bearing with Higher Wear Resistance, Soc. Autom. Engr. of Japan Rev. 21 (2000) 321-325.

[2] V. Bhattacharya and K. Chattopadhyay, Microstructure and wear behaviour of aluminium alloys containing embedded nanoscaled lead dispersoids. Acta Materialia. 52 (2004) 2293-2304. https://doi.org/10.1016/j.actamat.2004.01.020

[3] X.J. Ning, J.H. Kim, H.J. Kim, C.J. Li and C. Lee, Characteristics and heat treatment of coldsprayed Al-Sn binary alloy coatings, Surf. Coat. Technol. $202 \quad$ (2008) 1681. https://doi.org/10.1016/j.surfcoat.2007.07.026

[4] O.S. Fatoba E.T. Akinlabi and M.E. Makhatha. Effect of Process Parameters on the Microstructure, Hardness, and Wear Resistance Properties of Zn-Sn-Ti Coatings on AISI 1015 Steel: Laser Alloying Technique. Int. J. Surf. Sci. Eng. 11 (6) (2017) 489-511. https://doi.org/10.1504/IJSURFSE.2017.088969

[5] J. Qu and J.J. Truhan, An efficient method for accurately determining wear volumes of sliders with non-flat wear scars and compound curvatures, Wear 261 (2006) 848-855. https://doi.org/10.1016/j.wear.2006.01.009

[6] M. Sujata, S. Bhargava, S. Suwas and S. Sangal. On Kinetics of TiAl3 Formation during Reaction Synthesis from Solid Ti and Liquid Al, J. Mater. Sci. Lett. 20 (2001) 2207-2209. https://doi.org/10.1023/A:1017985017778

[7] X.F. Liu, Z.Q. Wang, Z.G. Zhang and X.F. Bian. The Relationship between Microstructures and Refining Performances of Al-Ti-C Master Alloys, Mater. Sci. Eng. A 332 (2002) 70-74. https://doi.org/10.1016/S0921-5093(01)01751-8

[8] R.O. Kaibyshev, I.A. Mazurina and D.A. Gromov, Mechanisms of Grain Refinement in Aluminum Alloys in the Process of Severe Plastic Deformation, Met. Sci. Heat Treat. 48 (2006) 57-62.

[9] R.L. Fleischer, D.M. Dimiduk and H.A. Lipsitt, Intermetallic Compounds for High Temperature Materials: Status and Potential, Annu. Rev. Mater. Sci. 19 (1989) 231-263. https://doi.org/10.1146/annurev.ms.19.080189.001311

[10] E.T. Akinlabi and S.A. Akinlabi, Effect of Heat Input on the Properties of Dissimilar Friction Stir Welds of Aluminium and Copper, Am. J. Mater. Sci. 2 (2012) 147-152. https://doi.org/10.5923/j.materials.20120205.03

[11] X. Gong, J. Lydon, K. Cooper, and K. Chou, Beam Speed Effects on Ti-6Al-4V Microstructures in Electron Beam Additive Manufacturing, J. Mater. Res. 29(17) (2014) 19511959. https://doi.org/10.1557/jmr.2014.125

[12] W. Meng, Z. Li, F. Lu, Y. Wu, J. Chen and S. Katayama, Porosity Formation Mechanism and its Prevention in Laser Lap Welding. J. Mater. Process. Technol. 214 (2014) 1658-1664. https://doi.org/10.1016/j.jmatprotec.2014.03.011 